ISSN: 2362-1303 (Paper) | eISSN: 2362-1311(Online)

JOURNAL OF ADVANCED ACADEMIC RESEARCH (JAAR) July 2016

\title{
COMPARATIVE STUDY ON DUAL AND TRIPLE THERAPY USING ORAL ANTIDIABETIC DRUGS IN TREATMENT OF TYPE 2 DIABETES MELLITUS
}

Shakya Sangita ${ }^{1}$, Bajracharya Smrity, Shakya Amit, Shakya Santosh, Chaudhary Shailendra, Gautam Suraj, Shankar Ravi

\section{Diabetes and Endocrinology Centre, Hanumansthan, Lalitpur, Nepal}

\begin{abstract}
Introduction: Type 2 diabetes mellitus is a progressive complex disorder so most patients require dual and triple therapy using glucose- lowering agents. Purpose:To find the effectiveness of the dual therapy [glimepiride and metformin] and triple therapy [glimepiride, metformin and pioglitazone] for glycemic control. Method: The prospective study was conducted in Diabetes and Endocrinology Centre including 112 patients with Type 2 diabetes treating with oral antidiabetic drugs. Patients, age group between 30-70 years having pre- prandial blood glucose $[\geq 110 \mathrm{mg} / \mathrm{dl}]$ and post-prandial blood glucose $[\geq$ $140 \mathrm{mg} / \mathrm{dl}]$ were included. They were grouped into dual and triple therapy according to treatment they received. The blood glucose level was examined after one week of initial drug therapy. Patients taking oral antidiabetic drugs along with insulin therapy were excluded. Result: Type 2 diabetes mellitus was prevalent in the age group between 50$60 y e a r s$. The reduction in pre-prandial blood glucose with dual therapy and triple therapy were $26.5 \%$ and $27.1 \%$ respectively and reduction in post-prandial blood sugar were 32.6 $\%$ and $30.5 \%$ respectively. Hence the effectiveness of the dual therapy $(p=0.827)$ and triple therapy $(p=0.949)$ was similar in pre and post glycemic control

Conclusion: The dual and triple therapy may be equally effective for the treatment of type 2 DM.
\end{abstract}

KEYWORDS: Type 2 DM, Biguanides, Sulphonylurea, Dual therapy, Triple therapy

\section{INTRODUCTION}

Diabetes is a group of disorders of carbohydrate meta olism in which the action of insulin is diminished or absent through altered secretion, decreased b insulin activity or combination of both factors (Amir, Linda, Sweet, Starkey, \& Shekelle, 2012). It is characterized by hyperglycemia, polyuria, polydipsia and glycosuria (Engelgau, Geiss, Saaddine, Boyle, Benjamin, \& Gregg, 2004). As the disease progresses tissue or vascular damage ensues leading to severe complications such as retinopathy, nephropathy, neuropathy, cardiovascular disease and foot ulceration (Engelgau, Geiss, Saaddine, Boyle, Benjamin, \& Gregg, 2004).According to World Health Organization (WHO), the 
ISSN: 2362-1303 (Paper) | eISSN: 2362-1311(Online)

\section{JOURNAL OF ADVANCED ACADEMIC RESEARCH (JAAR) July 2016}

worldwide prevalence of diabetes in 2000 was 171 million and is projected to rise to 366 million by 2030. Type 2 diabetes mellitus was found to be the most common. According to Nepal Diabetes Association, the estimated number of diabetes mellitus patients $(>20$ years) at the end of year 2002 was about 350,000 (Gerich \& E, 1998).

There are various oral hypoglycemic drugs available for treatment of Type 2 diabetes mellitus, among them Biguanides (91.9\%) and Sulfonylurea (86.5\%) were found to be the most commonly used followed by thiazolidinediones $(18.9 \%), \alpha$ - glucosidase inhibitors $(2.7 \%)$ and meglitinides $(0.9 \%)$ respectively (Bennett, Maruthur, Singh, Segal, Wilson, \& $\mathrm{R}, 2011)$. The dual therapy of sulphonylureasandbiguanides and multiple therapies of sulphonylrea, thiazolidinedione and biguanides are also used these days for effective treatment of type 2 diabetes mellitus.

Diabetes Mellitus is one of the most prevalent diseases and is a major concern in Nepal. Though the prevalence of Diabetes Mellitus is high, there have been few studies done on the efficacy of commonly used oral antidiabetic drugs in Type 2 Diabetes Mellitus in Nepalese population. This study is designed with an aim of comparing the effectiveness of dual [glimepiride and metformin] and triple therapy [glimepiride, metforminandpioglitazone]. Hence this study will try to suggest the appropriate drug therapy on the basis of safety profile in addition to efficacy shown by symptomatic relief and normal blood sugar level.

\section{METHODS}

This study was conducted in the "Diabetes and Endocrinology Center", Hanumansthan, Kupondole, Lalitpur, Nepal. This study was ethically approved by review committee of Diabetes and Endocrinology Center. The prospective study was carried out for duration of six months from July 2009 to January 2010.

A total of 111 type 2 diabetes mellitus (DM) visiting Out Patient Department of Diabetes and Endocrinology Center were enrolled. Patients in the age group between 30-70 years having pre- prandial blood glucose $[\geq 110 \mathrm{mg} / \mathrm{dl}]$ and post-prandial blood glucose $[\geq 140$ $\mathrm{mg} / \mathrm{dl}]$ receiving only oral antidiabetic drugs without insulin therapy were enrolled in this study.

Patients suffering from type 1 Diabetes Mellitus and Type 2 DM with other diseases like hypertension, cardiovascular disease, kidney disease, pregnant, smokers were excluded from the study.

First the patient's verbal consent was obtained and then information regarding age of the patient, family history, presenting symptoms including polyuria, polyphagia and polydipsia 
ISSN: 2362-1303 (Paper) | eISSN: 2362-1311(Online)

\section{JOURNAL OF ADVANCED ACADEMIC RESEARCH (JAAR) July 2016}

were recorded in patient's data collection form. Then pre-prandial and post prandial blood glucose level of all included patients was recorded based on hospital data.

Depending on the patient's condition, the physicians had grouped them into monotherapy (Glimepiride, metformin, Pioglitazone), dual therapy [sulphonylurea (Glimepiride) and metformin] and triple therapy [sulphonylurea (Glimepiride), metformin and thiazolidinediones (Pioglitazone)]. Enrolled patients were instructed to come for follow up after one week. During the follow up visit, pre-prandial and post-prandial blood sample were collected and laboratory investigation done.

All enrolled patients were strictly monitored with regard diet and exercise as per WHO diabetic diet guidelines. [19]

All the data collected were coded and entered in the computer for processing and analyzed using MS-Excel and SPSS 11.5 for Windows. The data was analyzed for skewness which is generally used to determine the frequency of the distribution. Then ANOVA test was performed.

\section{RESULT}

A total of 111 patients between the ages of 30-70 years were included in the study. Among them Type 2 diabetes mellitus was mostly prevalent in the working age group between 50 60 years $(33.3 \%)$ followed by $40-50$ years $(32.4 \%)$.

\section{Table 1: Incidence of type 2 DM in various age groups}

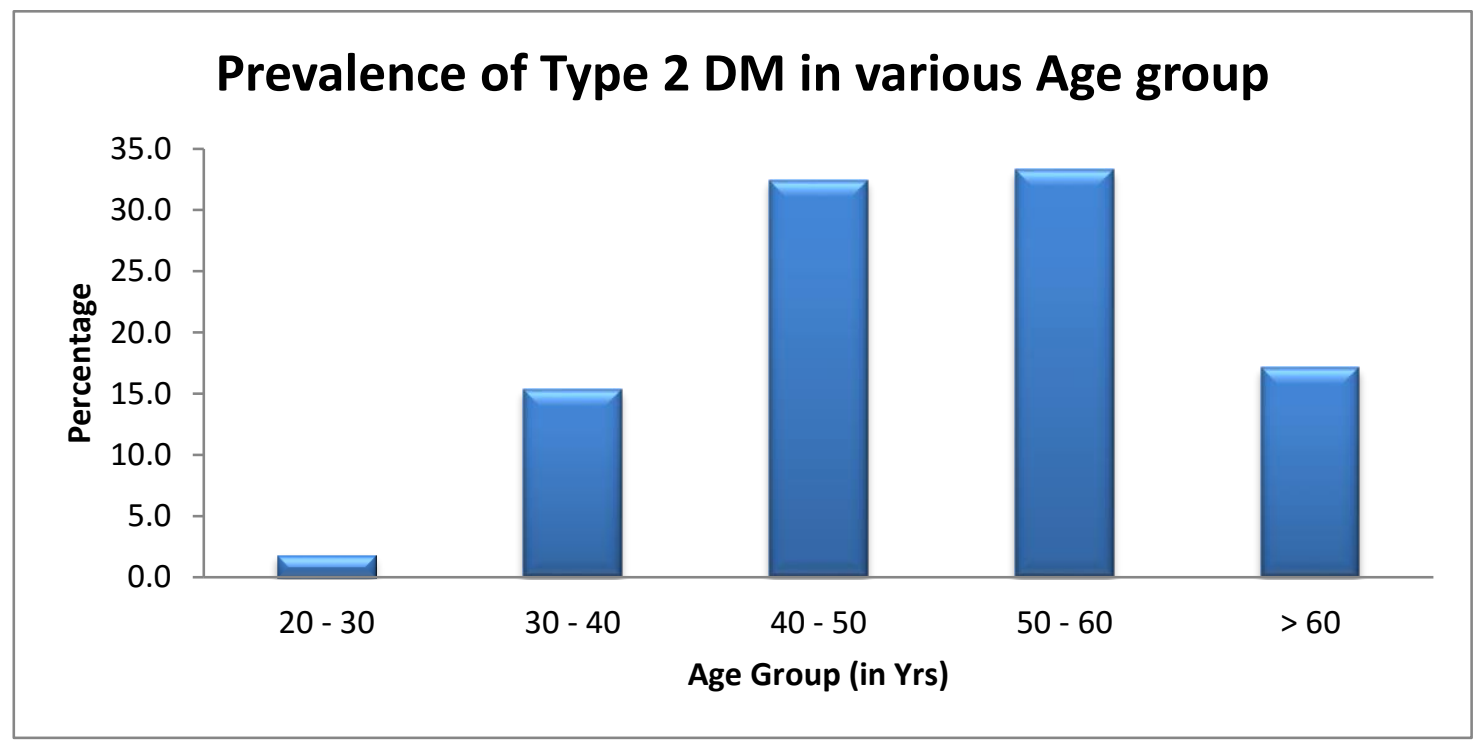

It was observed that $51.4 \%$ of patient of type-II diabetes mellitus had positive family history. 
ISSN: 2362-1303 (Paper) | eISSN: 2362-1311(Online)

\begin{tabular}{lll}
\hline DM-II & Frequency & Percentage \\
\hline Family history & 57 & 51.4 \\
Non-family history & 54 & 48.6 \\
Total & 111 & 100 \\
\hline
\end{tabular}

Common Sign and Symptoms of Type 2 DM:

From the study, frequent urination (51.4\%) and polydipsia (49.5\%) was found to be most common symptoms responded by patients.

Figure1: Common Sign and Symptoms of Type II DM

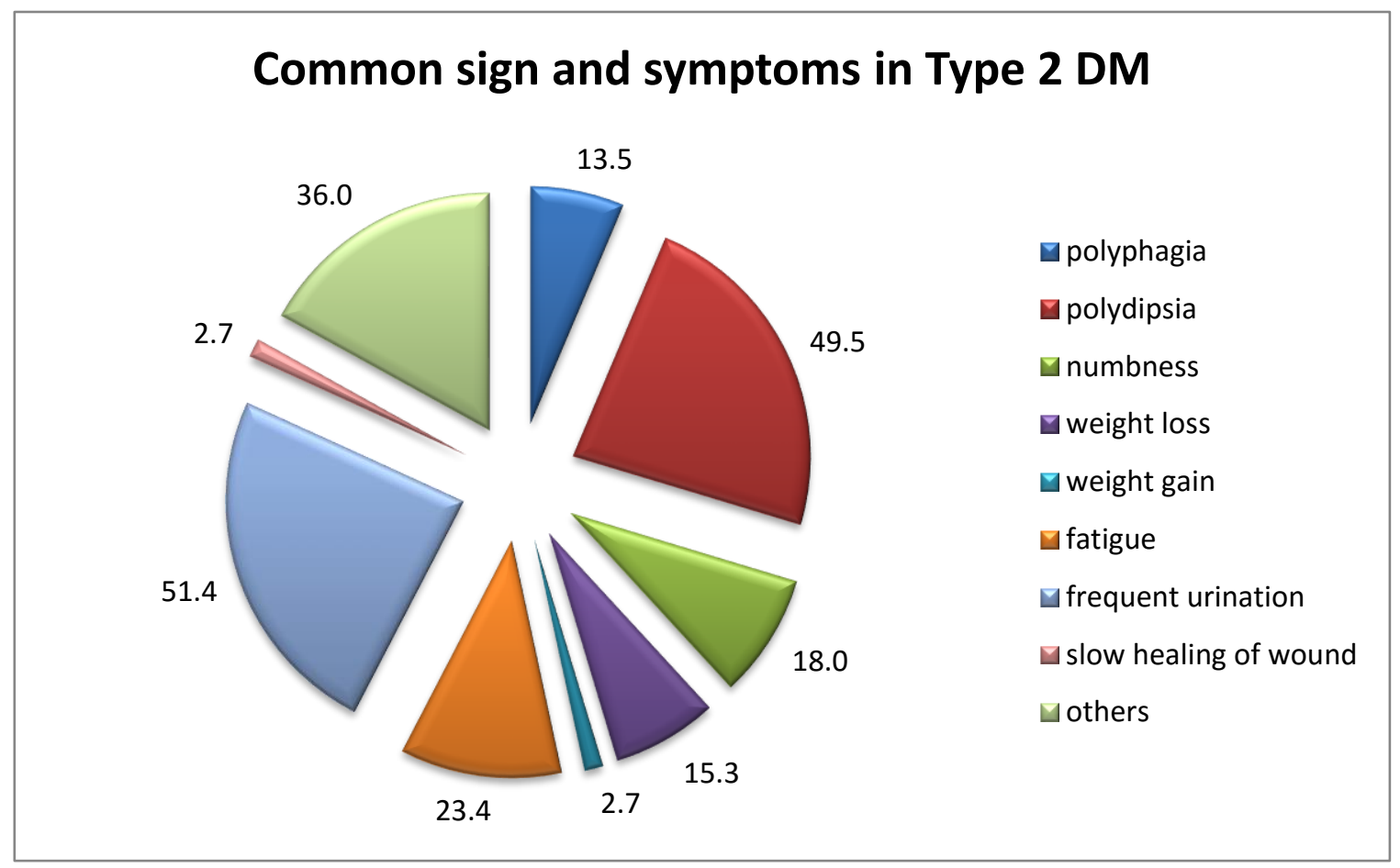

From the study, $45.9 \%$ of patient with BMI $(25-29 \mathrm{~kg} / \mathrm{m} 2)$ which is considered as an overweight, had type 2 diabetes mellitus.

As per prescription Biguanides (91.9\%) and Sulfonylurea (86.5\%) were found to be the most commonly used oral antidiabetic drugs among all oral antidiabetic groups which were followed by thiazolidinediones (18.9\%), $\alpha$-glucosidase inhibitor (2.7\%) and meglitinides $(0.9 \%)$ respectively. 
ISSN: 2362-1303 (Paper) | eISSN: 2362-1311(Online)

JOURNAL OF ADVANCED ACADEMIC RESEARCH (JAAR) July 2016

\section{Practice of prescribing oral antidiabetic drug in Type II DM}

\begin{tabular}{lll}
\hline Group & $\begin{array}{l}\text { Frequency } \\
(\mathbf{n = 1 1 1})\end{array}$ & Percentage \\
\hline Sulfonylurea & 96 & 86.5 \\
\hline Biguanides & 102 & 91.9 \\
Thiazolidinediones & 21 & 18.9 \\
$\boldsymbol{\alpha}$ - glucosidase inhibitor & 3 & 2.7 \\
Meglitinides & 1 & 0.9 \\
\hline
\end{tabular}

The dual therapy [sulphonylureas andbiguanides] and triple therapy [sulphonylurea, thiazolidinediones and biguanides] were found to be reduced by $26.5 \%$ and $27.1 \%$ respectively in pre prandial blood glucose and in post prandial $30.5 \%$ and $32.6 \%$ respectively. (Table 2)

\begin{tabular}{|c|c|c|c|}
\hline \multirow{2}{*}{ Drug } & \multicolumn{2}{|c|}{$\begin{array}{c}\text { Change in blood Glucose } \\
(\%)\end{array}$} & $\begin{array}{c}\text { No. of } \\
\text { subject }\end{array}$ \\
\hline & Pre prandial & post prandial & \\
\hline Biguanides & 17.9 & 21.8 & 9 \\
\hline Sulphonylureas & 15.1 & 39.1 & 5 \\
\hline Sulphonylureas + metformin & 26.5 & 30.5 & 55 \\
\hline $\begin{array}{c}\text { Sulphonylureas + metformin + } \\
\text { thiazolidinediones }\end{array}$ & 27.1 & 32.6 & 42 \\
\hline
\end{tabular}

Reductions are the average percentage change in blood glucose
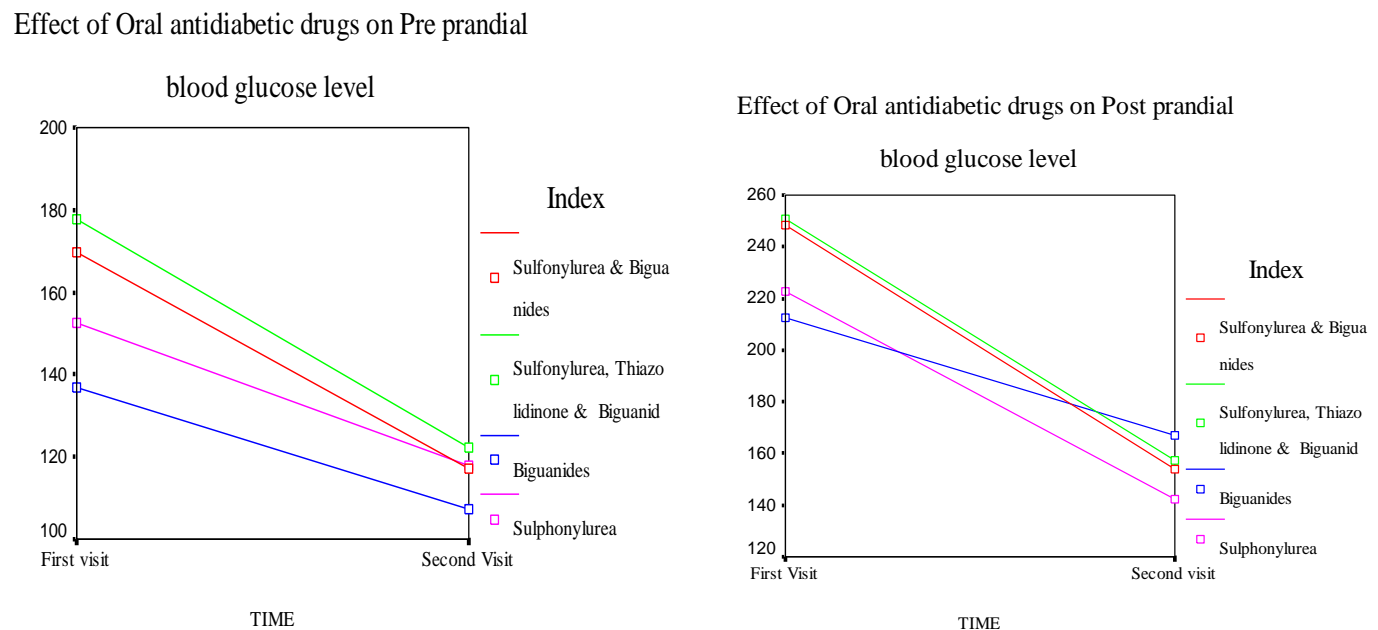
ISSN: 2362-1303 (Paper) | eISSN: 2362-1311(Online)

JOURNAL OF ADVANCED ACADEMIC RESEARCH (JAAR) July 2016

Fig 2(a)

Fig 2(b)

Effect of oral antidiabetic drugs on Fig( a) pre-prandial blood glucose level Fig(b) post prandial blood glucose level

The above Figure 2(a) showed that the pre-prandial blood glucose was $>160 \mathrm{mg} / \mathrm{dl}$ in the first visit and after taking dual and triple therapy, the blood glucose reduced to the normal range. The red line (dual therapy) and green line (triple therapy) seemed to be parallel and closer together.

Similarly in Figure 2(b) shows that post-prandial blood glucose was $>240 \mathrm{mg} / \mathrm{dl}$ in the first visit and after taking dual and triple therapy, the blood glucose level reduced to the normal range. The red line (dual therapy) and green line (triple therapy) seemed to be parallel and closer together. Hence the dual therapy is as effective as triple therapy in controlled of preprandial and post-prandial blood glucose.

\section{DISCUSSION}

From the study, it was found that, Type 2 diabetes mellitus is mostly prevalent in age group between 50-60years(33.3\%) and 40-50years(32.4\%) respectively. According to the Chennai Urban Rural Epidemiology study (CURES) eye study I, the prevalence of diabetes between 45 to 60 years of age group was nearly 25\% (Engelgau, Geiss, Saaddine, Boyle, Benjamin, \& Gregg, 2004) (Rema \& al, 2005).

Genetic factor is one of the predisposing factors of Non-Insulin Dependent Diabetes Mellitus because of monogenic defects in beta-cell function, which is characterized by onset of mild hyperglycemia at an early age (generally before age 25 years) (Gerich \& E, 1998). In this study, it was observed that $51.4 \%$ of patient of type-II diabetes mellitus had positive family history.

From the study, frequent urination (51.4\%) and polydipsia (49.5\%) was found to be most common symptoms responded by patients. Our study results are similar to the study conducted by McCulloch which states that the major three symptoms are polydipsia, polyuria and polyphagia (Roberts, tewart, Issa, Lake, \& Melis, 2005 Oct). These symptoms are caused by the effect of diabetes on the body. If the level of glucose in the blood becomes too high, glucose is improperly reabsorbed through the proximal renal tubuli. This results in higher levels of glucose being present in the urine (glycosuria) and in turn increases the osmotic pressure (Sheehan, 2003). This prevents water being reabsorbed by the kidney, resulting in greater urine production. This causes the patient to urinate frequently (Turner, CA, Frighi, \& Holman, 1999). 
ISSN: 2362-1303 (Paper) | eISSN: 2362-1311(Online)

\section{JOURNAL OF ADVANCED ACADEMIC RESEARCH (JAAR) July 2016}

According to the study done by Bays HE et al, over weight persons are at higher risk of insulin resistance because fat interferes with the body's ability to use insulin (Bays, Chapman, \& Grandy, 2007). In our study, $45.9 \%$ of patient with BMI between $25-29$ $\mathrm{kg} / \mathrm{m} 2$ which is considered as overweight had type 2 diabetes mellitus.

From our study, Biguanides (91.9\%) and Sulfonylureas $(86.5 \%)$ were found to be the most commonly used oral antidiabetic drugs among all drug groups followed by thiazolidinediones (18.9\%), $\alpha$-glucosidase inhibitors $(2.7 \%)$ and meglitinides $(0.9 \%)$ respectively. This complies with the study done by Stumvoll M et al(Stumvoll, Nurjhan, G, Dailey, \& JE, 1995). Biguanides has the potential advantage of targeting insulin resistance, rather than increasing plasma insulin concentration which is an early feature of the disease. So it was found to be the most commonly used oral antidiabetic drug. In addition, biguanides do not cause weight gain and may reduce adipose tissue mass. Thus they may be preferred in obese and non-obese patients with insulin resistance (Bennett, Maruthur, Singh, Segal, Wilson, \& R, 2011)(Stumvoll, Nurjhan, G, Dailey, \& JE, 1995).

From the literature, biguanides cause less fasting hypoglycemia compared to sulphonylureas (Cheng \& IG, 2005). Besides, sulfonylureas can cause weight gain and induce severe hypoglycemia. From this study we found that biguanide has got more advantages compared to sulfonylurea.

From the study the most commonly used drugs among the sulphonylurea group was glimepiride $(77.5 \%)$ followed by glicazide $(6.3 \%)$ and glibenclamide $(1.8 \%)$ respectively. Our study results are similar to those of the study done by RK Campbell [9]. In his study, Glimepiride is a sulfonylurea that is pharmacologically distinct from other sulfonylureas because of differences in receptor-binding properties and potentially selective effects on ATP-sensitive K+ channels (Tosi, Muggeo, Brun, Spiazzi, Perobelli, \& Zanolin, 2003). The pharmacokinetic profile of glimepiride makes it suitable for once-daily dosing and appears to be a useful option for patients with type 2 diabetes not controlled by diet and exercise alone and who want to achieve tight glucose control (Shimpi1, Patil1, Kuchake, P.V.Ingle1, Surana1, \& Dighore, 2009) (Campbell \& Glimepiride, 1998).

Several combinations of oral antidiabetic agents like sulfonylurea and metformin, a sulfonylurea plus an alpha-glucosidase inhibitor; a sulfonylurea, metformin and a thiazolidinedione have been shown to further improve glycemic control when compared to monotherapy (Riddle, 2000)Thiazolidinediones, sulfonylureas, and metformin produced similar reductions in hemoglobin $\mathrm{A}_{1 \mathrm{c}}$ levels when used as monotherapy. Combination therapies had additive effects, producing an absolute reduction in hemoglobin $\mathrm{A}_{1 \mathrm{c}}$ levels of about 1 percentage point more than monotherapy (Bolen, Feldman, Vassy, Wilson, \& al, 2007). 
ISSN: 2362-1303 (Paper) | eISSN: 2362-1311(Online)

\section{JOURNAL OF ADVANCED ACADEMIC RESEARCH (JAAR) July 2016}

The dual therapy of sulphonylureas + biguanides and triple therapies of sulphonylurea, thiazolidinediones and biguanides were found to reduce preprandial blood glucose by 26.5 $\%$ and $27.1 \%$ respectively and post prandial blood glucose by $30.5 \%$ and $32.6 \%$ respectively. This result has been supported by the study conducted by Qaseem A et al in 2007 (Qaseem, Vijan, Snow, Cross, Weiss, \& DK, 2007). In his study, high quality evidence showed that both therapy (dual and Triple) reduced blood glucose level to a similar degree. Metformin was more effective than other medications as monotherapy as well as when used in combination therapy with another agent for reducing blood glucose level (Qaseem, Vijan, Snow, Cross, Weiss, \& DK, 2007). However this result is not in compliance with the study conducted by Roberts VL et al, which showed that in patients with type 2 diabetes not adequately controlled by dual combination therapy with metformin and a thiazolidinedione, the addition of glimepiride improved glycemic control compared with placebo with an acceptable tolerability profile (Roberts, tewart, Issa, Lake, \& Melis, 2005 Oct) .

Our study showed that dual therapy (sulphonylurea and biguanide) and triple therapy (sulphonylurea, thiazolidinedione and biguanide) showed a similar reduction in pre and post prandial blood glucose levels.

\section{CONCLUSION}

There was no significant difference between dual and triple therapy with regard to lowering of blood glucose level in patients with type 2 diabetes mellitus. The reduction in the pre and post prandial blood glucose by dual and triple therapy was found to be statistically insignificant (pre and post parandial; $\mathrm{p}=0.827$ and 0.949 respectively). Hence from the study it can be concluded that the dual therapy is as effective as triple therapy in effective treatment of type 2 diabetes mellitus.

\section{LIMITATION}

- The study should be conducted in wide number of samples and in different centers and hospitals to get more generalizable results.

- The study period is short; hence the adequate time should be allocated for this kind of study.

\section{RECOMMENDATION}

- Dual therapy and triple therapy was found to be statistically insignificant, dual therapy can be used than triple therapy as triple therapy is not officially approved by FDA.

- As the study focuses on the effect of different group of antidiabetic drug, further study can be done on individual drug therapy. 
ISSN: 2362-1303 (Paper) | eISSN: 2362-1311(Online)

JOURNAL OF ADVANCED ACADEMIC RESEARCH (JAAR) July 2016

\section{ACKNOWLEDGEMENT}

We remain indebted to all the members of the "Diabetes and Endocrinology Center", Kupondole, for their kind support and co-operation for making this study successful. We are also grateful to all the patients for their kind co-operation.

Special thanks is owed to all those who have helped us directly and indirectly for the completion of the project.

\section{Bibliography}

Amir, Q., Linda, L., Sweet, D. E., Starkey, M., \& Shekelle, P. (2012). Oral

Pharmacologic Treatment of Type 2 Diabetes Mellitus: A Clinical Practice Guideline From the American College of Physicians. Ann Intern Med, 156, 219-31.

Bays, H., Chapman, R., \& Grandy, S. (2007). The relationship of body mass index to diabetes mellitus, hypertension and dyslipidaemia: Comparison of data from two national surveys. Int J Clin Pract, 61(5), 737-47.

Bennett, Maruthur, Singh, Segal, Wilson, \& R, C. (2011). Comparative effectiveness and safety of medications for type 2 diabetes: Anupdate including new drugs and 2-drug combinations. Ann Intern Med, 154, 602-13.

Bolen, S., Feldman, L., Vassy, J., Wilson, L., \& al, H.-C. Y. (2007). Comparative Effectiveness and Safety of Oral Medications for Type 2 Diabetes Mellitus. Ann of Internal Medicine , 147 (6), 386-399.

Campbell, R., \& Glimepiride. (1998). Role of a new sulfonylurea in the treatment of type 2 diabetes mellitus. Ann Pharmacother, 32 (10), 1044-52.

Cheng, \& IG, F. (2005). Oral antihyperglycemic therapy for type 2 diabetes mellitus. CMAJ , 172, 213-26.

Engelgau, M., Geiss, L., Saaddine, J., Boyle, J., Benjamin, S., \& Gregg, E. (2004). The evolving diabetes burden in the United States. Ann Intern Med, 140, 945-50.

Gerich, \& E, J. (1998). The genetic basis of type 2 DM: Impaired insulin secretion versus impaired insulin sensitivity. Endocrine Society journal , 19, 491-503.

Qaseem, Vijan, Snow, Cross, Weiss, \& DK, O. (2007). Clinical Efficacy Assessment Subcommittee of the American College of Physicians. Glycemiccontrol and type 2 diabetes mellitus: the optimal hemoglobin A1c targets. Ann Intern Med. , 147, 417-22.

Rema, M., \& al, S. P. (2005). Prevalence of Diabetic Retinopathy in Urban India:. The Chennai Urban Rural Epidemiology study (CURES) eye study Investigate Ophthalmology and Visual science , 46, 2328-2333. 
ISSN: 2362-1303 (Paper) | eISSN: 2362-1311(Online)

JOURNAL OF ADVANCED ACADEMIC RESEARCH (JAAR) July 2016

Riddle. (2000). Combining sulfonylureas and other oral agents. Am J Med. , 108.

Roberts, tewart, Issa, Lake, \& Melis. (2005 Oct). Triple therapy with glimepiride in patients with type 2 diabetes mellitus inadequately controlled by metformin and a thiazolidinedione: results of a 30-week, randomized, double-blind, placebo-controlled. Clin Ther , 27(10), 1535-47.

Sheehan, M. T. (2003). Current Therapeutic Options in Type 2 Diabetes Mellitus. Clinical Medicine \& Research , 3, 189-200.

Shimpi1, R. D., Patil1, P. H., Kuchake, V. G., P.V.Ingle1, Surana1, S. J., \& Dighore, P. N. (2009). Comparison of effect of metformin in combination with glimepiride and glibenclamide on glycaemic control in patient with type 2 diabetes mellitus. International Journal of PharmTech , 1(1), 50-61.

Stumvoll, Nurjhan, G, P., Dailey, \& JE, G. (1995). Metabolic effects of metformin in non-insulin-dependent diabetes mellitus. $N$ Engl J Med , 333(9), 550.

Tosi, F., Muggeo, M., Brun, E., Spiazzi, G., Perobelli, L., \& Zanolin, E. (2003).

Combination treatment with metformin and glibenclamide versus single-drug therapies in type 2 diabetes mellitus: a randomized, double-blind, comparative study. Metabolism. 52, 862.

Turner, CA, C., Frighi, \& Holman, R. (1999). Prospective Diabetes Study (UKPDS) Group: Glycemic control with diet, sulfonylurea, metformin, or insulin in patients with type 2 diabetes mellitus: progressive requirement for multiple therapies. JAMA , 281, 2005-12. 